\title{
Editorial
}

\section{Web 2.0 Special Issue}

Journal of Direct, Data and Digital Marketing Practice (2008) 9, 229-230.

doi:10.1057/palgrave.dddmp.4350104

There can be little doubt that Web 2.0 has been the 'hot' marketing topic of 2007 - something it might repeat in 2008. Strangely, for something that has attracted so much attention, it remains an ethereal and ill-defined subject. For many marketers the subtleties of Web 1.0 provide enough of a challenge without grappling with the complexity of its next phase of evolution.

The purpose of this special issue of the Journal is twofold. Firstly to demystify the subject and to decode the subject in marketing, not digital technology, terms. Secondly, to answer the 'so what' question. Everybody is aware of the phenomenal growth of companies like YouTube, MySpace and Facebook - but what, if any, is their real and lasting impact on the wider marketing environment?

Six years ago, following the bursting of the dot.com bubble, I wrote a paper for the Journal titled: 'The impact of new technologies - permanent paradigm shift or transitory aberration?' (Interactive Marketing, October-December 2002, Vol. 4, No. 2, pp. 144-155.) This paper concluded that the web had radically changed the company-customer relationship, in ways that were then only beginning to be understood. Is history repeating itself? Does Web 2.0 present the marketing community with the same level of challenges and opportunities as Web 1.0?

In producing this special issue, the Journal has sought the experiences of practicing marketers, from a wide spectrum of industries and professions.

The first and only paper from academia, is by Efthymios Constantinides and Stefan Fountain from the University of Twente, in the Netherlands. This paper, 'Web 2.0: Conceptual Foundations and Marketing Issues', explores the underlying principles of Web 2.0 and describes the new breed of applications it has enabled. The other contributors build upon the definitions and concepts contained in this paper.

Danny Meadows-Klue provides the first opinion piece with the intriguing title, 'Falling in Love 2.0'. This warns brand owners that Web 2.0 can be of inestimable assistance in their courtship with consumers but it can also provide the mechanisms to hasten a fast and messy divorce. Danny explains how the new generation of Web applications has radically and forever changed the relationship between brands and their customers.

Dr Jacques Bughin, a director of McKinsey \& Company, uses the consultancy's research to explain how companies are adopting the technology and the benefits they expect from their investments. McKinsey's research enables us to understand how marketers are employing Web 2.0 and gives examples of its applicability to improving customer service and enabling the co-creation of value with consumers.

There is nobody better placed than Alex Batchelor, Royal Mail's Marketing Director, to answer the question: 'What happens when direct mail meets Web 2.0'.

Alex's paper provides a fascinating explanation of the evolution of direct mail to what he labels, most appropriately, Mail 2.0. The evolution of mail and the Web to 'level 2.0' provides a perfect combination of channels to assist marketers to put the customer at the centre of their activities.

Yahoo! is one of the leading companies that emerged from the initial wave of web innovation. Glen Drury, the MD and VP of Yahoo! Northern Europe writes an opinion piece about the challenges for marketers to combine online advertising, social networking and user generated content. Glen explains that success in using Web 2.0 demands far more than learning a new 
set of skills - it demands a radical rethink in the balance of power and control between customer and supplier.

The primary objectives of my contribution, entitled 'Social networking: An age neutral commodity', are twofold. Firstly, to dispel the notion that users of Web 2.0 applications are limited to the digital media literate youth market. Secondly, to explain how today's uses of Web 2.0 provide a limited, and possibly misleading, insight into the potential of the technology to become a basic building block of all Web applications.

There follow two opinion pieces containing very different viewpoints. In the first, contributed by three Booz Allen consultants, Web 2.0 is described as a threat to companies stuck in a traditional market-to-the-masses mind-set, but as a powerful tool for competitive advantage for those willing to grasp the opportunities it provides.

Alan Mitchell, a contributing editor to Marketing Week, has the final word about the subject. Alan's advice to marketers is that they must learn to use the applications enabled by Web 2.0 in a passive and cooperative way rather than the directive and controlling ways of traditional marketing. This demands a different mental model as well as a different operational model. Alan concludes his opinion piece by saying: 'The real challenge of Web 2.0 is not 'out there'. It's in our heads.' He is absolutely right.

This special issue concludes with our regular Legal and Regulatory Update from Berwin Leighton Paisner LLP, who provide three key legal questions, and answers regarding social networking sites.

When all of the jargon and hype is stripped away from Web 2.0 we find a combination of exciting new ways for marketers to do the thing that should be at the centre of their universe - understanding and communicating with their customers.

Dick Stroud, Guest Editor Founder, 20plus30 Consultants 